\title{
Comparing EU Knowledge Among Leave and Remain Voters: A Replication Study
}

\author{
Noah Carl ${ }^{1}$ \\ 29 August 2019
}

${ }^{1}$ Independent researcher, UK: noah carl3742@hotmail.com 


\begin{abstract}
In a recent study, Carl et al. (2018) compared levels of EU knowledge among Leave and Remain voters using a 15-item EU knowledge quiz. Their quiz comprised 9 'ideologically neutral' items, as well as 6 items that they deemed more 'ideologically convenient' for one side or the other. They found that there was no average difference between Leave and Remain voters, but that Remain voters scored slightly higher on the 'ideologically neutral' items $(0.09 \mathrm{sd})$, whereas Leave voters scored slightly higher on the 'ideologically convenient' items $(0.12 \mathrm{sd})$. They also found that those who did not vote scored lower than those who did (0.38sd). The present study attempts to replicate Carl et al.'s findings using data from the British Election Study Panel. It reports a small average advantage for Remain voters, as compared to Leave voters, of $0.05-0.09 \mathrm{sd}$. In addition, it reports a large average advantage for voters, as compared to non-voters, of 0.64-0.70sd.
\end{abstract}

Key words: EU; Brexit; referendum; political knowledge; replication 


\section{Introduction}

In a recent study, Carl et al. [1] compared levels of EU knowledge among Leave and Remain voters using a 15-item EU knowledge quiz (and see [2]). They found that there was no average difference between Leave and Remain voters, but that Remain voters scored slightly higher on the 9 'ideologically neutral' items (0.09sd), whereas Leave voters scored slightly higher on the 6 'ideologically convenient' items (0.12sd). They also found that those who did not vote scored lower than those who did (0.38sd). The present study attempts to replicate Carl et al.'s findings using data from the British Election Study Panel. Replication studies are important for ensuring that scientific findings are robust [3], [4]. If a scientific finding replicates in several datasets, then one can be more confident that it is not attributable to the quirks of one particular dataset.

\section{Method}

Carl et al. [1] administered their 15-item EU knowledge quiz to a nationally representative sample of the British population via an online survey. Their data were collected in February and March of 2018, i.e., more than 18 months after the referendum took place. The authors made a number of key methodological decisions when designing their EU knowledge quiz. First, they opted for a simple true/false question format. Second, they included 9 'ideologically neutral' items as well as 6 'ideologically convenient' items, and were careful to include an equal number of items that were more 'ideologically convenient' for each side. Third, they included questions about several different aspects of the EU, which they anticipated would be of varying difficulty level. Fourth, they decided to omit a 'don't know' response category in order to obviate the possibility of biased coefficients stemming from differential guessing propensities. And fifth, they limited the response time for each item to 30 s in order to minimise the possibility of respondents looking up answers on their web browsers. See Section 2 of the original paper for further details.

The present study uses data from the British Election Study Panel (BES Panel), a 14-wave internet panel study that asks questions about respondents' political attitudes, party support and political behaviour [5]. Wave 1 was administered in February and March of 2014, while Wave 14 was administered in May of 2018. Hence the survey straddles the EU referendum itself, which took place in June of 2016. All the data were collected by the polling organisation YouGov.

Wave 8 of the BES Panel, which was administered just before the referendum in May and June of 2016, includes 6 EU knowledge items. (These are given in Table 1). Like in Carl et al.'s survey, each of these items was either true or false. However, unlike in their survey, there was a 'don't know' response category as well. None of the 6 EU knowledge items in the BES Panel is substantially more ideologically convenient' for one side or the other. 5 out of the 6 are without question 'ideologically neutral'. The only item which could be said to deviate slightly from neutrality is item 4 , given that some commentators have criticised the EU for spending too much on agricultural subsidies (e.g., [6], [7]). However, the item is not unambiguously more 'ideologically convenient' for Leave voters. Several other of the EU's spending 
functions have also come under criticism--including Eurozone bailouts, international aid and bureaucratic perquisites (e.g., [8], [9])--and these may be seen as even less legitimate than agricultural subsidies. The author confirmed that the correct answer to item 4 is 'true' by looking at the EU budget breakdown for 2016 [10]. Specifically, in column H ('EU-28') of the spreadsheet for '2016', the largest single budget item is 'European Agricultural Guarantee Fund'. There was no response timer for the BES Panel's EU knowledge items [11].

Two measures of EU referendum vote choice were utilised for the present study. The first was the respondent's actual referendum vote choice measured in Wave 9 of the survey, which was administered just after the referendum in June and July of 2016. The second measure was the respondent's vote intention, measured in Wave 8 of the survey. The main advantage of the former is that it provides the most valid measure of the respondent's underlying preferences. The main advantage of the latter is that it was observed in the same wave as the EU knowledge items, meaning that the relationship between those two variables will not be subject to biases associated with differential attrition. Actual vote choice was used as the default.

Consistent with Carl et al.'s methodology, the quickest $2 \%$ of respondents by total survey time were deleted prior to analysis. This resulted in 671 deletions. In addition, all respondents who gave their age as 'under 18' were deleted. This resulted in a further 513 deletions. Note that excluding these respondents did not materially affect any of the paper's main results. The BES Panel includes two sets of sample weights for each of the first 9 waves: 'full weights', and 'core weights'. The full-weights cover all respondents who took part in the relevant wave of the survey, while the core-weights cover a smaller more representative sample of respondents. Comparing these two variables generally yielded very similar results, so full-weights were used as the default. But some models were estimated separately with each of the two sets of weights.

\section{Results}

The distribution of respondents' scores is plotted in Figure 1, alongside the distribution that would be expected if respondents had been guessing on all items. The observed distribution had a mean of 2.5 and a standard deviation of 1.7, while the expected distribution had a mean of 3 and a standard deviation of 1.2. Respondents therefore scored lower on average than if they had been guessing on all items, which in contrast to what Carl et al. [1] observed. The most likely explanation for this discrepancy is that Carl et al. omitted a 'don't know' response category, whereas all the EU knowledge items in the BES Panel included one. And indeed, substantial percentages of respondents selected 'don't know'. For example, 45\% of respondents selected 'don't know' for item 1. Note that answers of 'don't know' were coded as incorrect.

Another observation that can be made about Figure 1 is that the distribution of observed scores is wider than the distribution of expected scores (consistent with the larger standard deviation reported above), which is in contrast to what Carl et al. observed. Again, this discrepancy is probably attributable to the fact that Carl et al. omitted a 'don't know' response category, which had the effect of forcing respondents who didn't know the answer to take a guess. 
Table 1 displays the percentage of respondents answering each item correctly, along with the corresponding percentages for respondents who said they voted Leave or Remain in Wave 9. Interestingly, only 1 out of 6 items was answered correctly at a rate significantly better than chance, namely item $2(p<0.001) .4$ out of 6 items were answered correctly at a rate significantly worse than chance $(p<0.001)$. EU knowledge score was standardised for subsequent analyses.

Overall, Remain voters scored slightly but significantly higher than Leave voters (full weights: $0.08 \mathrm{sd}, p<0.001$; core weights: $0.09 \mathrm{sd}, p<0.001$ ). Likewise, respondents who intended to vote Remain at Wave 8 scored slightly but significantly higher than those who intended to vote Leave, although here the difference was even smaller (full weights: 0.05sd, $p=0.002$; core weights: $0.06 \mathrm{sd}, p<0.001$ ). These results are broadly consistent with what Carl et al. observed. They found that there was no overall difference between Leave and Remain voters, but that Remain voters scored slightly higher on the 'ideologically neutral' items $(0.09 \mathrm{sd})$, whereas Leave voters scored slightly higher on the 'ideologically convenient' items $(0.12 \mathrm{sd})$. Given that 5 out of the 6 items in the present quiz are without question 'ideologically neutral', the small average advantage for Remain voters of $0.05-0.09$ sd is closely in line with what Carl et al. observed. However, it should be noted that Carl et al. urged caution in interpreting the differences they observed on the 'ideologically neutral' and 'ideologically convenient' items, given that they were small in magnitude and were discovered ex-post, rather than having been predicted in advance.

Respondents who said they voted at Wave 9 scored substantially higher than those who said they did not (full weights: $0.64 \mathrm{sd}, p<0.001$; core weights: $0.65 \mathrm{sd}, p<0.001$ ). Likewise, respondents who intended to vote at Wave 8 scored substantially higher than those who intended not to vote or said 'don't know' (full weights: 0.70sd, $p<0.001$; core weights: 0.69sd, $p<0.001$ ). These results are again broadly consistent with what Carl et al. observed. They found that those who did not vote scored lower than those who did $(0.38 \mathrm{sd})$. Hence the difference observed here is in the same direction, but is somewhat larger in magnitude. This is most likely due to lower measurement error, stemming from the absence of a 'don't know' option.

Table 2 displays estimates from OLS models of EU knowledge score, using actual vote choice as the independent variable of interest. Note that the sample sizes for these models are slightly smaller, owing to missing values on covariates. The differences between Leave and Remain voters become much smaller and are rendered non-significant when covariates are introduced. By contrast, the differences between non-voters and those who did vote remain moderate and statistically significant. Consistent with what Carl et al. observed, older age, male gender, white ethnicity and higher education are all significant predictors of EU knowledge. Somewhat surprisingly, respondents aged 26-45 scored slightly lower on average than those aged 18-25. Models with additional covariates (but smaller sample sizes) are provided in Table $\mathrm{S} 1$ in the online appendix.

Table 3 displays estimates from OLS models of EU knowledge score, using vote intention as the independent variable of interest. Once again, the differences between Leave and Remain voters become much smaller and are rendered non-significant when covariates are introduced, whereas the differences between non-voters and those who intend to vote remain moderate and statistically significant. Consistent with what Carl et al. observed, older age, male gender, white ethnicity and higher education 
are all significant predictors of EU knowledge. The results in Table 3 are also highly similar to those in Table 2.

A number of robustness checks were carried out. First, two alternative measures of EU knowledge score were computed: one using principal components analysis, and one using item response theory. However, these were so highly correlated with one another, and with the original measure of EU knowledge score, that no further analyses were conducted (see Table S2 in the online appendix; all $r$ 's > $.97, p<0.001)$. Second, the initial comparisons between Leave and Remain voters, and between voters and non-voters, were re-run without applying sample weights. Results were essentially identical (Remain advantage: $0.09 \mathrm{sd}, p<0.001$; voter advantage: $0.62 \mathrm{sd}, p<0.001$ ). Third, the initial comparisons were rerun using a measure of EU knowledge score that excluded item 4. Again, results were essentially identical (Remain advantage: $0.08 \mathrm{sd}, p<0.001$; voter advantage: $0.63 \mathrm{sd}, p<0.001$ ).

\section{Discussion}

In a recent study, Carl et al. [1] compared levels of EU knowledge among Leave and Remain voters using a 15-item EU knowledge quiz (and see [2]). The present study has attempted to replicate Carl et al.'s findings using data from the British Election Study Panel (BES Panel).

Overall, the results were broadly consistent with those observed by Carl et al. They found that there was no average difference between Leave and Remain voters, but that Remain voters scored slightly higher on the 'ideologically neutral' items $(0.09 \mathrm{sd})$, whereas Leave voters scored slightly higher on the 'ideologically convenient' items $(0.12 \mathrm{sd})$. The present study reported a small average advantage for Remain voters, as compared to Leave voters, of $0.05-0.09$ sd. Given that 5 out of the 6 items in the present study were 'ideologically neutral', this result is closely in line with what Carl et al. observed. There is now evidence from two separate surveys that Remain voters had a small advantage, when compared with Leave voters, in knowledge about 'ideologically neutral' aspects of the EU.

Carl et al. also found that those who did not vote scored lower than those who did (0.38sd). The present study reported a large average advantage for voters, as compared to non-voters, of 0.64-0.70sd. Hence the difference observed here was in the same direction, but was somewhat larger in magnitude. Based on the preceding results, it would be fair to say that the most important difference in EU knowledge was between those who voted and those who did not vote, rather than between Leave voters and Remain voters. All else being equal, an increase in turnout above the level that actually obtained would have resulted in voters with less knowledge about the EU being recruited into the electoral process.

It should be noted that the present study was not an exact replication of Carl et al.'s study. Although both studies were based on online surveys, Carl et al.'s data were collected more than 18 months after the referendum took place, whereas the BES Panel data were collected 1-2 months before. Carl et al.'s EU knowledge quiz was made up of 9 'ideologically neutral' items and 6 'ideologically convenient' items, whereas the quiz utilised in the present study was made up of 5 'ideologically neutral' items and 1 ambiguous item. Carl et al.'s EU knowledge items did not include a 'don't know' response 
category, whereas the BES Panel's items did include such a category. Finally, Carl et al. limited the response time for each item to 30s, whereas there was no such limit for the BES Panel's items.

\section{Acknowledgements}

The author is grateful to the British Election Study team for making their data available to other researchers.

\section{References}

[1] N. Carl, L. Richards, and A. Heath, "Leave and Remain voters' knowledge of the EU after the referendum of 2016," Elect. Stud., vol. 57, pp. 90-98, 2018.

[2] N. Carl, "Are Leave Voters Less Knowledgeable About The EU Than Remain Voters?," What UK Thinks: EU, 2018. [Online]. Available: http://archive.fo/MBOna.

[3] OpenScienceCollaboration, "An open, large-scale, collaborative effort to estimate the reproducibility of psychological science," Perspect. Psychol. Sci., vol. 7, no. 6, pp. 657-660, 2012.

[4] OpenScienceCollaboration, "Estimating the reproducibility of psychological science: Studies for Replication," Science (80-. )., vol. 349, 2015.

[5] E. Fieldhouse, J. Green, H. Schmitt, van der Eijk, J. Mellon, and C. Prosser, "British Election Study Internet Panel Waves 1-14.," British Election Study, 2018. [Online]. Available: http://archive.fo/4JPBX.

[6] G. Monboit, "The one good thing about Brexit? Leaving the EU's disgraceful farming system," Guardian, 2018.

[7] J. Crisp, "EU's wasted billions on green farming subsidies strengthen case for Brexit," Telegraph, 2017.

[8] A. Barker, P. Spiegel, and G. Parker, "David Cameron frustrated as UK dragged into Greece bailout," Financial Times, 2015.

[9] L. McKinstry, "Why must Britain pay for Brussels' reckless spending?," Daily Express, 2014.

[10] EuropeanCommission, "EU expenditure and revenue 2014-2020," [website for the Europan Commission], 2018. [Online]. Available: http://archive.fo/suU68.

[11] E. Fieldhouse, "[Email from Ed Fieldhouse to Noah Carl]," Personal communication, 2019. . 


\section{Tables and Figures}

Figure 1. Distributions of observed scores and scores expected under guessing.

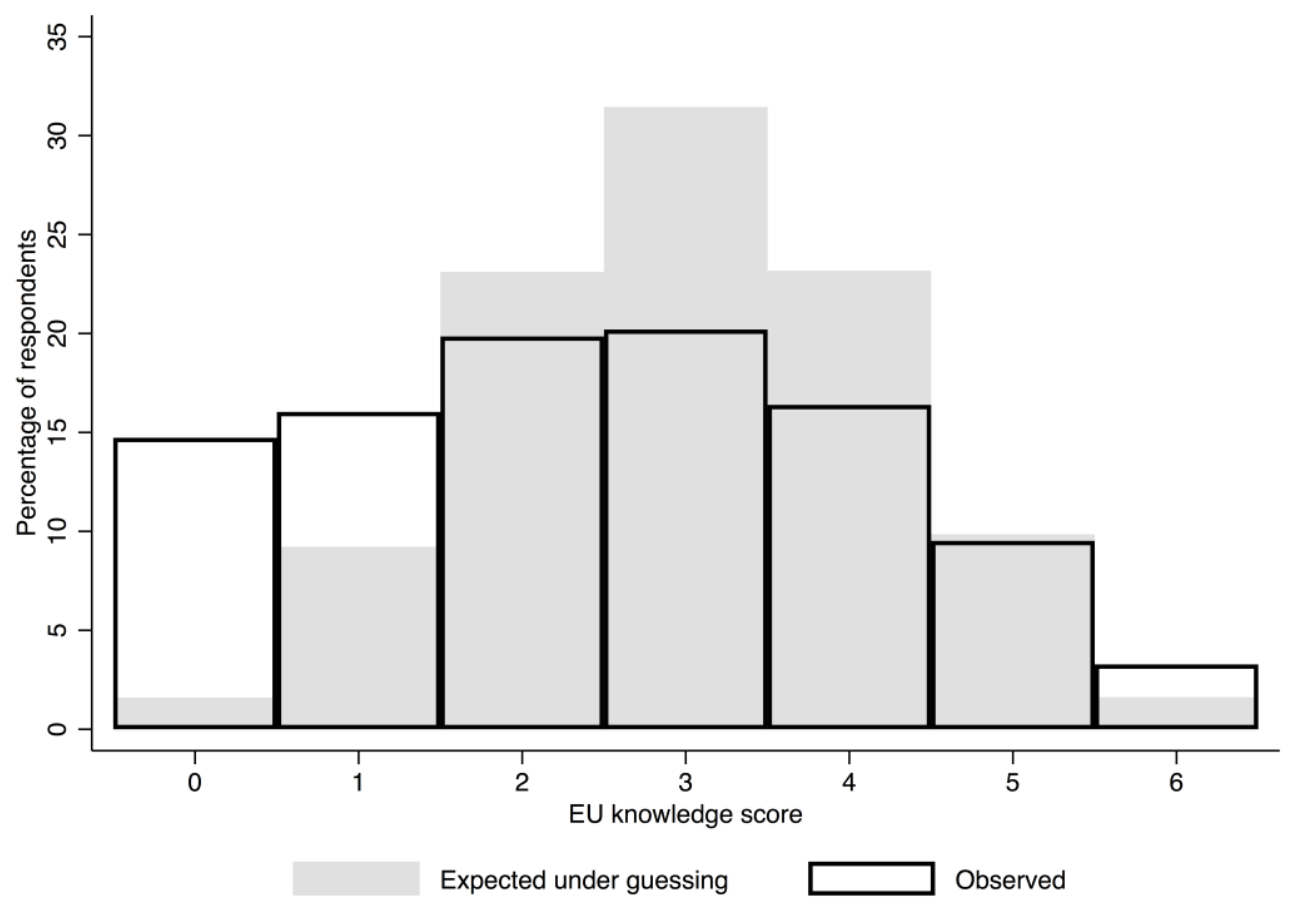

Notes: Expected scores were simulated using the 'rbinomial' function in Stata. Full sample weights were applied. 
Table 1. Percentages of respondents answering each item correctly.

\begin{tabular}{lccc}
\hline \multicolumn{1}{c}{ Item } & Full sample & Voted Leave & Voted Remain \\
\hline 1. Each EU Member State elects the same number of representatives & 41 & 42 & 43 \\
to the European Parliament [F] & 70 & 73 & 72 \\
2. Switzerland is a member of the EU [F] & 35 & 33 & 39 \\
3. Croatia is a member of the EU [T] & 33 & 34 & 36 \\
4. The EU spends more on agriculture than any other policy area [T] & 20 & 19 & 23 \\
$\begin{array}{l}\text { 5. The European Court of Human Rights only has jurisdiction over EU } \\
\text { members [F] }\end{array}$ & 49 & 50 & 52 \\
6. The European Union is made up of 15 member states [F]
\end{tabular}

Notes: Correct answers are given in square brackets. Leave and Remain voters were defined as those who reported that they voted Leave or Remain in Wave 9. Full sample weights were applied. Unweighted $n$ for the full sample = 32,318 . Unweighted $n$ for the sample of voters $=26,492$. 
Table 2. Estimates from OLS models of EU knowledge score using actual vote choice as the independent variable of interest.

\begin{tabular}{|c|c|c|c|c|}
\hline & \multicolumn{2}{|c|}{ Full sample weights } & \multicolumn{2}{|c|}{ Core sample weights } \\
\hline & $\begin{array}{l}\text { EU knowledge } \\
\text { score } \\
\text { (standardised) }\end{array}$ & $\begin{array}{l}\text { EU knowledge } \\
\text { score } \\
\text { (standardised) }\end{array}$ & $\begin{array}{c}\text { EU knowledge } \\
\text { score } \\
\text { (standardised) }\end{array}$ & $\begin{array}{c}\text { EU knowledge } \\
\text { score } \\
\text { (standardised) }\end{array}$ \\
\hline \multicolumn{5}{|c|}{ EU referendum vote (ref. = Leave) } \\
\hline Remain & $0.08^{* * *}$ & 0.02 & $0.08^{* * *}$ & 0.02 \\
\hline Did not vote & $-0.58^{* * *}$ & $-0.43^{* * *}$ & $-0.59^{* * *}$ & $-0.45^{* * *}$ \\
\hline \multicolumn{5}{|l|}{ Age group (ref. = 18-25) } \\
\hline $26-35$ & & $-0.14^{\star *}$ & & $-0.16^{* * *}$ \\
\hline $36-45$ & & $-0.10^{*}$ & & $-0.12^{* *}$ \\
\hline $46-55$ & & $0.16^{* * *}$ & & $0.14^{\star * *}$ \\
\hline $56-65$ & & $0.32^{\star \star \star}$ & & $0.32^{* * *}$ \\
\hline $66+$ & & $0.38^{* * *}$ & & $0.38^{* * *}$ \\
\hline \multicolumn{5}{|l|}{ Gender (ref. = Female) } \\
\hline Male & & $0.59^{\star \star \star}$ & & $0.61^{\star * *}$ \\
\hline Ethnicity (ref. = Non-white) & & 0.00 & & 0.00 \\
\hline White & & $0.31^{* * *}$ & & $0.27^{* * *}$ \\
\hline \multicolumn{5}{|c|}{ Education (ref. = Below secondary) } \\
\hline Secondary & & $0.11^{* * *}$ & & $0.12^{\star \star *}$ \\
\hline Post-secondary & & $0.29^{\star \star \star}$ & & $0.30^{\star * *}$ \\
\hline University degree & & $0.55^{\star \star \star}$ & & $0.56^{\star \star *}$ \\
\hline \multicolumn{5}{|l|}{ Region (ref. = North East) } \\
\hline North West & & $0.10^{*}$ & & $0.09^{*}$ \\
\hline Yorkshire and the Humber & & $0.09^{*}$ & & 0.07 \\
\hline East Midlands & & $0.17^{\star * *}$ & & $0.15^{\star *}$ \\
\hline West Midlands & & $0.20^{* * *}$ & & $0.17^{* * *}$ \\
\hline East of England & & $0.18^{* * *}$ & & $0.15^{\star * *}$ \\
\hline London & & $0.24^{* * *}$ & & $0.20^{* * *}$ \\
\hline South East & & $0.20^{\star * *}$ & & $0.20^{\star * \star}$ \\
\hline South West & & $0.20^{* * *}$ & & $0.19^{* * *}$ \\
\hline Wales & & $0.15^{\star \star \star}$ & & $0.13^{* *}$ \\
\hline Scotland & & $0.20^{* * *}$ & & $0.18^{* * *}$ \\
\hline Unweighted $n$ & 23,632 & 23,632 & 15,007 & 15,007 \\
\hline$R^{2}$ & 0.02 & 0.18 & 0.02 & 0.19 \\
\hline
\end{tabular}

Notes: Entries are coefficients from OLS models. 'ref.' denotes the reference category for each variable. Standard errors are omitted for the sake of brevity. Significance levels, based on robust standard errors: $+10 \%,{ }^{*} 5 \%$, ${ }^{* *} 1 \%$, *** $0.1 \%$. 
Table 3. Estimates from OLS models of EU knowledge score using vote intention as the independent variable of interest.

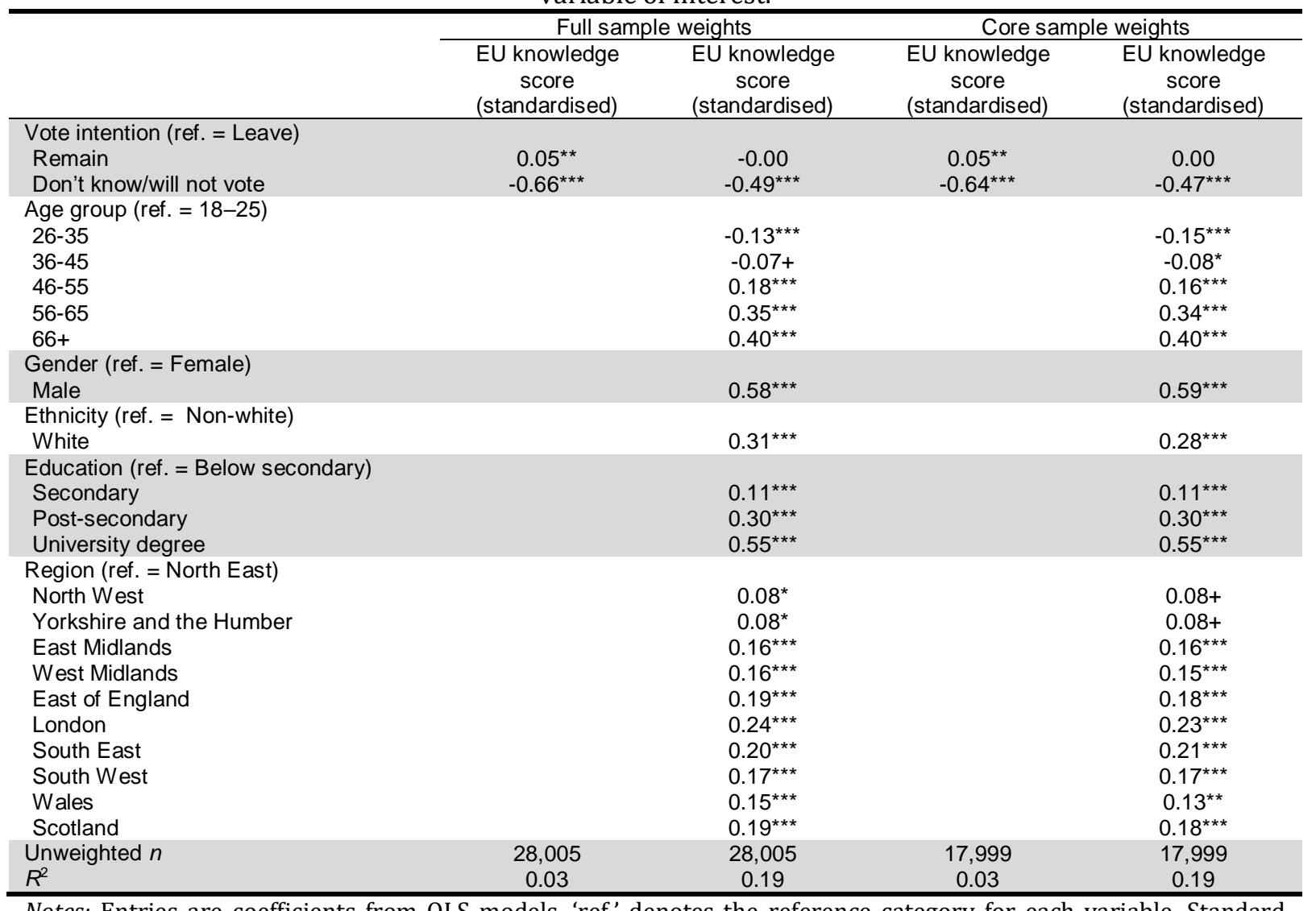

Notes: Entries are coefficients from OLS models. 'ref.' denotes the reference category for each variable. Standard errors are omitted for the sake of brevity. Significance levels, based on robust standard errors: $+10 \%,{ }^{*} 5 \%$, ${ }^{* *} 1 \%$, *** $0.1 \%$. 